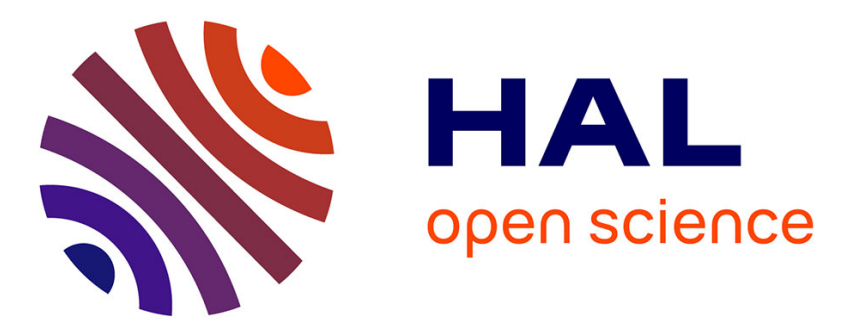

\title{
Knowledge integration based on roadmapping and conceptual framework approach to ease innovation management
}

\author{
Nicolas Perry, Wilhelm Uys
}

\section{- To cite this version:}

Nicolas Perry, Wilhelm Uys. Knowledge integration based on roadmapping and conceptual framework approach to ease innovation management. International Journal of Computer Applications in Technology, 2010, 37 (3/4), pp.165 - 181. 10.1504/IJCAT.2010.031933 . hal-00517231

\section{HAL Id: hal-00517231 \\ https://hal.science/hal-00517231}

Submitted on 16 Dec 2012

HAL is a multi-disciplinary open access archive for the deposit and dissemination of scientific research documents, whether they are published or not. The documents may come from teaching and research institutions in France or abroad, or from public or private research centers.
L'archive ouverte pluridisciplinaire HAL, est destinée au dépôt et à la diffusion de documents scientifiques de niveau recherche, publiés ou non, émanant des établissements d'enseignement et de recherche français ou étrangers, des laboratoires publics ou privés. 


\title{
Knowledge Integration based on Roadmapping and Conceptual Framework Approached to ease Innovation Management
}

\author{
NICOLAS PERRY*, \\ Research Institute on Communication and Cybernetic of Nantes, UMR CNRS 6597 \\ Ecole Centrale Nantes, 1, rue de la Noé, 44321 Nantes, France \\ E-mail: Nicolas.Perry@irccyn.ec-nantes.fr \\ *Corresponding author \\ WILHELM UYS \\ Department of Industrial Engineering, \\ Stellenbosch University, Matieland, Stellenbosch, 7602, South Africa,
}

\begin{abstract}
Knowledge management and innovation management are logically linked. However, the alignment of their respective deployment mechanisms is still not obvious. An analysis of the Innovation and Knowledge Life Cycles shows that the Knowledge Life Cycle can be deployed (partially) at each step of the Innovation Life Cycle. This implies that different, specific knowledge management tools could be used to increase innovation. Two knowledge management tools are considered in this paper: roadmaps and conceptual frameworks. A methodology is proposed for using roadmaps and conceptual frameworks within the context of integrated knowledge networks for improving efficient innovation. These two approaches aim to ease the knowledge structuring and identification in order to facilitate innovation. Two knowledge management examples in the financial services highlight how these tools contribute to the increased efficiency of the innovation process, leading to a more mature innovation deployment.
\end{abstract}

Keywords

Innovation, Knowledge Integration, Knowledge Management, Roadmapping, Innovation Management, Conceptual Framework

\section{Introduction}

Innovation is today widely recognised by both industry and academics as a necessity for any business that wants to remain competitive and survive and grow (Drucker, 1985; IBM's Global Innovation Outlook, 2005). Surveys such as the annual innovation survey from The Boston Consulting Group (2005) however, suggest that although the importance of innovation is fully realised by most companies and they continue to spend more and more on innovation, many do not seem to generate satisfactory profit or competitive advantage. The problem does not seem to lie in the invention part or the generation of innovative ideas, but more in the successful management of the innovation process from an idea to a successful product in the market (Kemp et al., 2003; Lööf et al., 2002).

More and more researchers are emphasising the importance of knowledge management for supporting the efficient management of innovation (Johannessen et al., 1999; Pérez-Bustamante, 1999; Carneiro, 2000; Burgelman et al., 2001; Darroch et al., 2002; Lemon et al., 2004). The way in which knowledge is used, spread and stored by an organisation's employees determines whether this organisation has a culture stimulating or restraining innovation. Innovation in effect happens through the novel combination of existing internal and new external knowledge. In order to innovate effectively and sustainably, existing knowledge should therefore not only be captured, but also shared and integrated. By sharing best practices, inefficient redundancy in innovation is greatly reduced, whereas the integration of knowledge helps to exploit complementarities among knowledge assets and to achieve coordination. Actual practises of achieving this sharing and integration is however currently not well understood (Leiponen, 2006, Du Plessy, 2005).

The purpose of this paper is to present the mutual enrichment of using on the one side conceptual framework to structure and clarify knowledge, and on the other side roadmaps methods of working. A methodology has been developed for an efficient application of these two elements - as knowledge management support tools - for the improved management and deployment of innovation projects. These tools are specifically aimed at capturing, modelling, contextualising and sharing of existing enterprise knowledge in order to improve the process of innovation.

The paper starts with a brief overview of the innovation process and knowledge management. This is followed by a section explaining a methodology developed by the teams. The methodology entails the 
application of roadmaps and conceptual frameworks as knowledge management support tools for the management of innovation. Finally, example applications in financial services companies are discussed. We will end the discussion with the open issues of knowledge maturities evaluation and the knowledge networks that become the new informal structure of collaboration.

\section{Innovation Management}

Over the last few years much has been written about innovation and many have tried to uniquely and precisely define innovation (Drucker, 1985; Tidd et al., 2001). Innovation is traditionally viewed as a linear progression from research to invention, from engineering design to product, and from manufacturing to marketing. This model suggests that innovation can be increased by increasing R\&D inputs (technology push). Innovation is however much more complex than a sum of knowledge inputs. It is about successful market outcomes and the process by which those outcomes are generated. A very thorough definition of innovation is provided by Salvendy (1992, p.1170): "Innovation is not just one simple act. It is not just a new understanding or the discovery of a new phenomenon, not just a flash of creative invention, not just the development of a new product or manufacturing process; nor is it simply the creation of new capital and markets. Rather innovation involves related creative activity in all these areas. It is a connected process in which many and sufficient creative acts, from research through service, are coupled together in an integrated way for a common goal." The 21 st Century Working Group has defined innovation as follows: "Innovation transforms insight and technology into novel products, processes and services that create new value for stakeholders, drive economic growth and improve standards of living." (Donofrio, 2004). This definition acknowledges that innovation is a complex and multidimensional activity that cannot be characterised by a single input measure.

Innovation is therefore not simply an invention or novel idea, but is the complete process of developing the idea and successfully exploiting it in the enterprise and the market.

Tidd et al. (2001) view innovation as a process that needs to be managed. According to them organisations essentially have to manage four different phases in the innovation process of turning ideas into successful reality:

(i) Scan: Scan and search their environments (internal and external) to pick up and process signals about potential innovation.

(ii) Select: Strategically select from this set of potential triggers for innovating those things which the organisation will commit resources to doing.

(iii) Plan: Having chosen an option, organisations need to resource it - providing (either by creating through R\&D or acquiring through technology transfer) the resources to exploit it.

(iv) Implement: Finally organisations have to implement the innovation, growing it from an idea through various stages of development to final launch - as a new product or service in the external market place or a new process or method within the organisation.

Innovation management is therefore about learning to find the most appropriate solution to the problem of consistently managing this process. This paper suggests an innovation management framework that is based on the successful management of knowledge along the complete Knowledge Life Cycle as defined in the following section.

\section{Knowledge Integration as Support for Innovation Management}

Knowledge management leads to knowledge integration in order to ease and optimise works efficiency. It has received widespread attention in recent years as an important basis for competitive advantage (Prax, 2000; Grundstein, 1999).

Before discussing the importance of knowledge management for the efficient management of innovation, the concepts of knowledge and the Knowledge Life Cycle, as well as knowledge management needs to be defined.

The Cambridge dictionary defines knowledge as the understanding of, or information about, a subject which has been obtained by experience or study, and which is either in a person's mind or possessed by people generally. Knowledge is the baseline from which innovation occurs, and against which innovation is measured. Without knowledge, innovation would be a random, uncontrollable and unsustainable activity. Figure 1 illustrates how knowledge evolves from a concept to usable knowledge while supporting the innovation process associated with the material supply chain. Knowledge is thus an asset that must be collected, protected, accessed, maintained and managed - therefore the need for Knowledge Management and toolsets that makes this possible.

Figure 1: The Knowledge Supply Chain 


\subsection{Roadmapping and conceptual framework for knowledge management}

Various definitions for knowledge have been given in the research literature. According to Davenport and Prusak (1998), knowledge is "a fluid mix of framed experience, values, contextual information, and expert insights and grounded intuitions that provides a framework for evaluating and incorporating new experiences and information. It originates and is applied in the minds of the knower. In software organizations, it often becomes embedded not only in documents or repositories, but also in organisational routines, processes, practices, and norms". The debate normally goes around the differences between data, information, and knowledge (Frank \& Gardoni, 2005). Davenport and Prusak (1998) view the differences between data, information and knowledge as gradual, different levels of the same thing in which human interpretation makes the difference. Data becomes information if one adds context, categories or calculations. Information turns into knowledge if humans add their experience, judgement, values and beliefs to use it for comparison, decision-making and conversations. Bellinger (2004) adds to the definition of knowledge by adding that beyond context and relation there is a pattern that embodies both a consistency and completeness of relations which, to an extent, creates its own context. Pattern also serves as an archetype with both an implied repeatability and predictability. According to Bellinger, when a pattern relation exists amidst the data and information, the pattern has the potential to represent knowledge. It only becomes knowledge, however, when one is able to realize and understand the patterns and their implications. We postulate that knowledge results from the use of information created by human interpretation

Knowledge can further be classified into tacit or explicit knowledge (Nonaka, 1991). Explicit knowledge is the kind of knowledge that can be codified in documents, such as a case study, a technical description or procedures (which comes close to the definition of information). Tacit knowledge, on the other hand, is what resides in people's heads and comes out during action, as they make decisions or value judgements. According to Wenger, Mc Dermott \& Snyder, (2002, p.9) tacit knowledge consists of "embodied experience - a deep understanding of complex, independent systems that enables dynamic responses to context-specific problems." Therefore, "Sharing this kind of knowledge requires interaction and informal learning processes such as storytelling, conversation, coaching and apprenticeship." Although these distinctions between knowledge and information on the one hand and tacit and explicit knowledge on the other seems to overlap, the importance of these distinctions lies in the fact that only information and explicit knowledge can be exchanged through documents, while the more tacit knowledge can only be exchanged during human interaction. "Organisations need to find a balance between managing tacit and explicit knowledge, taking advantage of both the informal learning processes, as well as keeping track of it by codifying knowledge." (Van't Hof, 2003).

Knowledge Management has been defined in many different ways. Rus et al. (2001) has compiled the following definition from different sources: "Knowledge management is seen as a strategy (or practice, systematic process, set of policies, procedures and technologies) that creates, acquires, transfers, brings to the surface, consolidates, distils, promotes creation, sharing, and enhances the use of knowledge (or information, intellectual assets, intellectual capital) in order to improve organisational performance; support organisational adaptation, survival and competence; gain competitive advantage and customer commitment; improve employees' comprehension; protect intellectual assets; enhance decisions, services, and products; and reflect new knowledge and insights". Therefore, the activities of knowledge management should enable the creation, communication, and application of knowledge; and they should drive the capability of creating and retaining a greater value onto the core business competencies (Tiwana, 2001, Gunnlaugsdottir, 2003).

A knowledge management methodology and tool should support all the life cycles phases of knowledge. Consolidated from MOKA (MOKA Consortium, 2001) and Kads (Wielinga, 1992) methodology, a synthetic Knowledge Life Cycle is illustrated in Figure 2. It is designed to generalise the integration of expertise in computer-aided systems.

Figure 2: The Knowledge Life Cycle (Candlot et al., 2005)

This Knowledge Life Cycle consists of the following phases:

(i) Identification and Extraction: Identifying and collecting valuable knowledge from internal and external sources, as well as generating new knowledge.

(ii) Classification, Structuring, Formalisation and Storage: Methods of structuring and storing knowledge. Somehow the knowledge has to be classified and valued in terms of context, relevance and lifespan.

(iii) Refinement, Development, Sharing and Dissemination: Giving access to knowledge and distributing or transferring it. 
(iv) Diffusion: The application and use of knowledge in processes, products and services.

(v) Maintenance: Measuring the value and improving assets/KM - The knowledge has to be evaluated and improved.

In order to support the Knowledge Life Cycle, tools are required to navigate, structure, formalise and share the piece of knowledge. In the next sections, we will describe how conceptual frameworks and roadmaps are tools to support Knowledge Management.

3.1.1. Roadmaps

Roadmaps are structures that are becoming increasingly popular mechanisms to represent project paths, life cycles and processes (Kappel, 2000; Kostoff et al., 2001; Phaal et al., 2004). Various definitions have been given for roadmaps and roadmapping:

(i) "A roadmap is a layout of paths that exist (or could exist) in some particular geographical space. It is a metaphor for planning science and technology resources." (Co-operative Technology Roadmapping, TOA, TU Delft 2003)

(ii) Definition of the European Industrial Research Management Association (EIRMA): "The generic roadmap is a time-based chart, comprising a number of layers that typically include both commercial and technological perspectives. The roadmap enables the evolution of markets, products and technologies to be explored, together with the linkages and discontinuities between the various perspectives. The roadmapping technique can be seen to draw together key themes from the technology strategy and transitions literature, by the use of its layered structure in conjunction with the dimension of time." (Phaal et al., 2004)

For the purpose of this paper a roadmap is defined as a layout of descriptive paths that multidisciplinary teams can use as a guiding framework for collaborative efforts towards a common goal. The roadmap consists of beacons or waypoints that describe "where" to go, "how" to get there in the best possible way, and the "what" in terms of specific targets or goals to aim for. The beacons or way points should also have controls to ensure that the traveller reach the goals effectively and efficiently. All information collected while travelling on the roadmap path or paths should also be collected and managed to ensure that the actual trails followed can be backtracked in case he or she gets lost or to make it easier for future travellers. To summarise, a roadmap should contain the following elements (refer to Figure 3):

(i) A structured high-level framework consisting of desired beacons or way points ("where").

(ii) Objectives indicating "what" to aim for in order to reach a beacon or way point.

(iii) Descriptions and guiding information defining best practise methods on "how" to reach the beacons or way points.

(iv) Controls in order to manage efficiency and effectiveness.

(v) Information repository to collect information while travelling along a path.

A roadmap therefore provides the guiding structure that helps collaborative teams to focus endeavours within a set of project constraints, while still sustaining an environment with enough freedom for teams to innovate. Roadmaps can also be part of other roadmaps. They are all built up out of steps where one step in one roadmap can also be part of another roadmap. This means that one roadmap can have a relation with many other roadmaps, while the other roadmaps do not necessarily have to be related. This also means that information within these roadmaps can be shared and used in many other roadmaps. This network of roadmaps contains relationships between different points of information and because of these relations all information in the roadmap network is actually an ontology. This implies that there are different ways to get to the same piece of information or said otherwise, out of different perspectives. The same thing is possible with geographical roadmaps; the shortest route, the fastest route or the most cultural route. They will all take the traveller from point A to B and might use the same places or roads.

The beacons or way points can be organised in two ways:

(i) Along a logical time based progression towards specific goals or objectives (e.g. a life cycle of a project), or

(ii) In a classification structure organised according to the function, behaviour, or construction components of a specific domain (e.g. an organisational structure). In this arrangement the beacon points provide guidance for locating specific entities, instead of a time-phased journey towards a specific destination (the roadmap structure in this case therefore serves the purpose of a guiding structure to be used in an information repository)

Roadmaps can be used as an important tool for structuring and managing the information and explicit knowledge required for innovation. Specifically, it is supports the following aspects of innovation:

(i) Planning for Innovation: Roadmaps help to strategically direct and plan for innovation efforts. It can be used for example to map technology developments or market changes and to setup a 
Master Plan for the implementation of innovation projects. Innovation is driven by a number of external and internal drivers. It is important to align a sustainable plan for execution with these drivers. Roadmapping can be extensively used for this alignment and common understanding. Implementing Innovation: Roadmaps provide the structure to guide the efficient implementation of innovation.

(iii) Knowledge Management: A repository roadmap structure can be used for the management of knowledge to guide users in capturing, storing and finding information in context. It is also useful for mapping the life cycle of knowledge.

(iv) Life Cycles: Roadmaps provide the structure to manage the life cycle of en entity such as an enterprise, product, technology, knowledge, etc.

Figure 3 shows a graphical depiction of a roadmap structure with beacons containing guiding information, objectives, and controls, as well as an information repository.

\section{Figure 3: Roadmap with Guiding Structure and Beacons}

Roadmaps serve as a mechanism to guide stakeholders along the path of reaching a certain goal as well as a means to collect information, in context of the journey, during the journey. Roadmaps however, are not good mechanisms to provide one with the understanding of the terrain - in terms of entities and their relations - encountered during the journey. The next section will describe how conceptual frameworks address this gap.

\subsubsection{Conceptual frameworks}

Conceptual frameworks are aimed at providing stakeholders with a common understanding of how everything fits together, although they do not focus on the way to reach the goals set out in roadmaps. Conceptual frameworks can be compared to tourist guides describing the culture, vegetation, animal life, scenic sites, restaurants, etc. of the areas one are passing through during the hypothetical journey. A conceptual framework enables stakeholders to understand the different aspects of their environment and serves as a mechanism to contextualise any entity in the given environment. This improved understanding then facilitates the process of analysing the environment in order to make appropriate decisions or take the desirable actions.

Conceptual Framework is defined as: "A conceptual framework is a formal way of thinking (i.e. conceptualising) about a process/system under study." (Racunas et al., 2003). For the purpose of this paper the definition was broadened by substituting the terms "process/system" in the definition above for the term "domain" in order to make the definition more widely applicable. Moreover, a domain is defined as: "An area of knowledge or activity characterised by a set of concepts and terminology understood by practitioners in that area." (Booch et al., 1998).

A domain may therefore represent a knowledge area (e.g. manufacturing), a department in an organisation (e.g. Sales and Marketing), a certain information system (e.g. an ERP system), etc. It further has a defined scope and consists out of certain components (i.e. entities) having interactions/dependencies (i.e. relations) on other components of the domain. Generally, these domain components can be modelled as entities and the various interactions/dependencies as relations between the entities of the domain resulting in a network/framework for the given domain.

For the purpose of this paper the term Conceptual Framework (CF) will mean: "A formal model of a given domain, consisting out of the domain components (i.e. entities) and the relations existing among these components, used for understanding and analysing the domain in question."

The Conceptual Framework therefore contains the generic entities, i.e. "things" that are significant in the domain in question. Employees, projects, suppliers, raw material, products, parts, strategic objectives, departments, deliverables, documents, information systems, etc. are examples of typical Conceptual Framework entities of an organisation. In order to maximise the value embodied in a Conceptual Framework, and to avoid misinterpretation and misunderstandings, the syntax (i.e. structure) and semantics (i.e. meaning) used in the Conceptual Framework need to be clearly defined.

On a higher level, the Conceptual Framework can be viewed in the context of a broader management framework (Phaal et al., 2001) depicted in the diagram below (Shehabuddeen et al., 2000).

Figure 4: A Meta-framework for Management Representations and Approach 
Figure 4 shows the relation between the representation of a given system (i.e. domain) and the approach in which this representation is used to achieve certain actions, and decisions concerning the system. The four dimensions illustrated in this picture may be explained as follows:

(i) Conceptual: Concerned with the abstraction or understanding of a situation.

(ii) Applied: Concerned with concrete action or application in a practical environment.

(iii) Static: Concerned with the structure and position of elements within a system.

(iv) Dynamic: Concerned with causality and interaction between the elements of a system.

Similarly, the Conceptual Framework needs to include these dimensions in order to assist stakeholders to have a common understanding of the domain - in terms of structure and interaction between the entities to facilitate the process of making sensible abstractions about the entities of the domain necessary to instigate appropriate, concrete actions to benefit the domain as a whole.

As example, Figure 5 illustrates a partial view of a Conceptual Framework of an insurance company in terms of the relations among a number of its key entities. This Conceptual Framework was built using Organon wich is an ontology viewer and editor. This particular example shows that Admin Clarks and an information system called Phoenix, are required to execute the Claims process. It further shows that the Claims process is described in a document called Claims Process Definition and that another document, called Phoenix Requirements, contains the specifications of the Phoenix system. This simple view enables the user to quickly assess the entities related to the Claims process and serves as starting point for exploring the relevant Conceptual Framework further using appropriate software.

Figure 5: Example of Entities and Relations in the Conceptual Framework of a Life Insurance Company

In summary, Conceptual Frameworks can be exploited as a tool for contextualising and analysing the information and explicit knowledge required for innovation. The following facets of innovation are supported by Conceptual Frameworks:

(i) Planning for innovation: Conceptual Frameworks may be used to understand the relations between the different drivers for innovation in order to align views of high-level stakeholders to arrive at a common understanding. Furthermore, the Conceptual Framework can be used to highlight the main entities impacted by the changes implied by the planned innovation project. This supports the assessment of the planned innovation, which is required to determine the right course of action in terms of realising innovation.

(ii) Implementing innovation: Conceptual Frameworks provide a mechanism to analyse the domain in question to determine the most suitable actions required to realise the efficient implementation of innovation.

(iii) Knowledge management: Conceptual Frameworks contextualise the entities of interest in the domain where the innovation project is implemented. More specifically, it explains the relations between different terminology sets and bridges the views from different stakeholders, e.g. procurement, design, production, marketing, quality insurance, etc. It aims to provide one with the bigger picture of the landscape where the innovation project is implemented as well as with the details of the various entities present in this landscape and how they are related.

(iv) Life Cycles: Conceptual Frameworks give the interdependencies or relations between the different life cycles of interest in the domain in question, e.g. enterprise, product, technology, and Knowledge Life Cycles.

\subsection{The relationship between the knowledge and innovation life cycles}

Park et al. (2005) notes that the relation between Knowledge Management (KM) and Research and Development (R\&D) management is intrinsically close, because R\&D processes can primarily be seen as $\mathrm{KM}$ processes, transforming information on technological advancements and market demands into the knowledge needed for new product concepts and process designs. Interestingly and even surprisingly, however, the link between KM and R\&D management has been virtually inexistent. They conclude that, no matter how large the database is, how fast the engine is, or how exquisite the portal is, the KM system is futile unless it contributes to the creation of lucrative innovations and the development of new products. Pérez-Bustamante (1999) explains different types of innovation as a flux of knowledge: defensive innovations take into account information about the competitive situation and the market demand, while offensive innovations exploit information about scientific and technical advances in order to reach a favourable position in the market. Radical innovations are the product of putting together unlikely bits of information in an irregular, serendipitous process which is not encouraged by bureaucratic and non-agile 
organisations. Agility and speed to innovate in response to the environment may arise from: commitment to activities that create new knowledge bases, deployment of incremental innovations, exploitation of corporate intelligence, adoption of a horizontal management style that avoids unnecessary communication layers with management, and achieving a full integration and dissemination of knowledge within the organisation while maintaining its flexibility.

Swan et al. (1999) concluded that KM initiatives that encourage active networking are key to interactive innovation processes, but warns that an over-emphasis on building IT-based network links may ironically undermine rather than increase this.

There is thus consensus that successful and sustainable innovation is dependent on the ability of innovators to use knowledge management tools and techniques to:

(i) Analyse market needs, trends and opportunities,

(ii) Capture the outputs of innovation projects to preserve "corporate memory" for analysis and future use,

(iii) Re-use the outputs from previous projects or other groups, to accelerate the current innovation efforts with the co-operative knowledge captured before, and

(iv) Link innovation project members together and collaborate with other groups so as to expand the participating community, therefore expanding the ability to learn from others and innovate faster.

Both innovation and knowledge have specific, but related life cycles. The authors' view of the Innovation Life Cycle is described as part of the proposed methodology in section 3.1. The Knowledge Life Cycle consists of the following phases:

(i) Identification and Extraction: Knowledge is identified and extracted from other sources.

(ii) Structuring and Formalisation: Knowledge is structured and formalised in the selected knowledge management tools.

(iii) Refinement and Development: Knowledge is analysed, refined and further developed.

(iv) Dissemination: Distribution of applicable knowledge to people that requires it.

(v) Maintenance: Maintaining the knowledge, to ensure it remains up to date and applicable to the domain.

An innovation project will typically incorporate more than one Knowledge Life Cycle. The authors argue that there is actually a Knowledge Life Cycle "spiral" that happens during the execution of an innovation project, whereby the knowledge is repeatedly captured, refined, disseminated and maintained, depending on the progress and success of each phase of the innovation project, and the knowledge sub-domains under investigation during the project phase. Figure 6 illustrates the correlation between the Knowledge and Innovation Life Cycles (large circles in this figure depict strong, positive correlation between the phases of the two life cycles, whereas smaller circles present lower correlation levels between phases). For example, during the "Identify Internal and External Drivers" phase of the Innovation Life Cycle, most of the Knowledge Life Cycle is addressed, but most of the energy is spent on the "Identification and Extraction" phase, and nearly nothing on the "Maintenance" phase.

However, this illustrates that throughout the Innovation Life Cycle, there is a significant dependence on knowledge management.

Figure 6: The Correlation between Knowledge and Innovation Life Cycles

To summarise, innovation feeds on the abundant availability of reliable and applicable knowledge, and the ability to access, analyse, synthesize, and share this knowledge. In turn, the outputs of innovation projects contribute to the pool of knowledge, thereby incubating opportunities for future innovation.

\section{Radmapping and Conceptual Framework Based Methodology for Supporting Innovation Management}

The previous sections highlighted the importance of innovation for the competitiveness of a business. In order to have successful innovations, enterprises should learn to successfully manage the complete process of innovation. Since innovation within in an enterprise goes hand in hand with the adoption or development, and diffusion of new knowledge, knowledge management is a very important supporting function for innovation management. The concepts of roadmaps and conceptual frameworks were also explained in previous sections. This section describes the suggested methodology framework for using these knowledge management tools as support for innovation management.

\subsection{Proposed methodology}

The proposed methodology (framework) describes how the knowledge management tools (conceptual frameworks and roadmaps) support the management of innovation along its life cycle. This methodology 
focuses on the internal development and market diffusion of innovative services, products, or business models by a commercial enterprise. Similarly it also focuses on the successful and/or innovative exploitation of externally developed innovations (which could be either new or old technology) within an enterprise. This framework is depicted in Figure 7. It shows the proposed general Innovation Life Cycle model that serves as the framework for the proposed methodology. At the core of this innovation model lays market value. The aim of the whole innovation effort should be to increase the market value of the enterprise.

Figure 7: Innovation Life Cycle Model

The three planning terms - strategic, tactical and operational planning - distinguish the different types of projects within the enterprise. We assume that innovation should be driven using a top down approach by planning and developing innovation projects on a strategic and tactical level, and then deploying and monitoring/evaluation on an operational level. The methodology is described according to the following steps of the proposed Innovation Life Cycle:

(i) Identification of Internal and External Innovation Drivers: The innovation process can be initiated by various internal and/or external drivers. If innovation is to help a business grow and improve its competitiveness, it is important to plan the innovation carefully. Though some innovation drivers may change unpredictably, an organisation requires a strategic vision of how it wants the business to develop. This will help to focus its innovative efforts on the most important areas. Innovation has to be a product of an ongoing well-structured process that captures and evaluates innovation regularly. It should not wait for the innovation to happen arbitrarily, but should proactively plan for regular periodical meetings that will address innovation, market trends, competitive landscape, new technology availability and changes in customer preferences in order to create an environment conducive to innovative thinking. Roadmaps can serve as a very useful tool in this stage of the innovation process to strategically direct and coordinate team efforts for innovation. Its main application in this stage is to map current and future technology developments or market changes. Roadmapping provides a focus for scanning the environment and a means of tracking the performance of individual, including potentially disruptive, technologies. It represents a powerful technique for supporting innovation planning, especially for exploring and communicating the dynamic linkages between technological resources, organisational objectives and the changing environment. The final result of this stage of the innovation process should therefore be roadmaps that capture and contextualise knowledge about the evolution of markets, products and technologies to be explored, together with the linkages and discontinuities between the various perspectives (refer to Figure 8).

Figure 8: Schematic Technology Roadmap, showing how Technology can be aligned to Product and Service Developments, Business Strategy, and Market Opportunities.

(ii) Assessment: This stage of the innovation process involves assessing the impact of the identified potential innovation drivers from the previous stage. The next step is to determine what the impact will be of such changes on the current enterprise. This will identify and clarify potential innovation projects. Due to complex interdependencies inherent in the systems of interacting parts of the enterprise and its projects, models are required to gain a better understanding of the As-Is state of the enterprise. This will assist to determine which improvements are required to achieve the To-Be state of the enterprise, and what will be the impacts on the organisation. At present only a fraction of the enterprise domain is covered by available modelling conventions and tools. Conceptual frameworks are proposed as a way of modelling enterprise concepts or entities within the whole enterprise domain, along with their relations. This will improve understanding of the domain, and also helps with the identification and evaluation of potential innovation projects.

(iii) Planning the Project Portfolio: This stage of the innovation process involves the identification and prioritisation of projects that, once implemented, will result in an organisation moving from a current (As-Is) state to a future (To-Be) state. Transition paths are identified and evaluated. Once these transition paths are combined, with clearly defined objectives and allocated resources and budgets, a Master Plan roadmap is used to specify and select projects for deploying the transition paths. Once selected and prioritised, the different projects are then arranged in a portfolio of 
innovation projects. The basic function of the Master Plan roadmap is to define and build the infrastructure (the "what") and the architecture (the "how") for the project or projects that needs to be initiated to drive the enterprise through the required change. The outcome of the Master Plan is a prioritised list of innovation projects (which defines the innovation project portfolio). By ordering the implementation of a variety of innovation projects it ensures that the required resources and knowledge are available during each project and that there is integration between different projects.

(iv) Development/ Design: The Master Plan roadmap in the previous stage defined different innovation projects to be implemented. These innovation projects were planned on a tactical level. When these innovation projects are finally launched for implementation, the first stage of the project involves a detailed design or development of the proposed innovation. Different design teams are normally involved in such an innovation project, and they all need to be guided throughout the design phase of the project (in terms of their specific design objectives as well as providing them with best practise experience from previous designs). Roadmaps, constructed according to the required activities of the different design teams, provide the structure or framework to guide the design activities of the different teams by providing them with best practise knowledge and information in context with where it is required. The design roadmap also provides the structure for capturing and storing all design information and explicit knowledge developed during the design process. This is important for ensuring a successful implementation of the innovation and the transfer of the innovation to operations.

(v) Implementation: The implementation phase entails the roll-out of the completed designed or developed innovation within the enterprise. It is therefore the handover form design to operations and involves the actual use or operation of the new innovation within the enterprise. Roadmaps are again useful to manage the handover of the newly developed knowledge to the operational side of the enterprise. At this stage the conceptual framework model of the enterprise should be updated to reflect the new enterprise architecture. This conceptual framework model of the new enterprise can then be used in the next innovation cycle.

(vi) Monitor and Evaluate: This is the optimisation phase of the new implemented innovation. Once in operation the performance of the new innovation can be monitored and adjustments made to improve the innovation. Knowledge obtained from the operation of the innovation should be collected and stored in both a roadmap structure as well as the conceptual framework in order to guide future improvements or re-designs.

In order to support the use of knowledge in the Innovation Life Cycle, a number of tools can be used. We propose using Roadmapping and Conceptual Frameworks throughout this life cycle as shown in Figure 9:

(i) During the analysis of the drivers and the setup of the Market, Product or Service and Technology models, roadmapping can be used to guide the users, and capture the knowledge within context.

(ii) In order to assess the current situation (As-Is), conceptual frameworks can be best used to understand the inter-relations within the current situation.

(iii) When planning the Project Plan portfolio, a Master Plan Roadmap can again be used to create the overall structure and direction.

(iv) As each subproject is planned and executed in the Design and Development phases, several corresponding roadmaps can be used by each team.

(v) During implementation (roll-out) roadmaps as well as conceptual frameworks can again be used to understand the impact of the roll-out schedule, and how to best sequence the roll-out.

(vi) And, eventually, when the final service or project needs to be maintained, a new updated conceptual framework, that now models the new (To-Be) situation, can be used for support.

Figure 9: Tools to be used in the Proposed Methodology

\subsection{Knowledge maturity for innovation}

As illustrated in the previous section, innovation actually involves the identification; development and diffusion of new knowledge to an enterprise. In order to effectively use knowledge for the management of innovation, an enterprise should achieve a certain level of maturity with regards to the management of knowledge. The goal is to ensure that the innovation process can be accelerated, is repeatable and sustainable.

In order to ensure efficient innovation management, two aspects have to be measured. On the one hand, it is important determine the value added by the innovation so as to evaluate the impact of knowledge 
gained and innovation achieved, and on the other hand, the organisational maturity to reflect the ability to change and evolve quickly to reach the goals.

The value could be directly linked to the innovation project, but could also be more widely distributed within the global enterprise. Value indicators can be for the product (design or manufacturing), the time to delivery reduction, the technology gap with competitors, or the manufacturing rate. As presented in the introduction, the enterprise value no longer only applies to the physical aspects, but shifts to intellectual capital and knowledge assets that are more abstract and are therefore more difficult to define, model and evaluate. The overall knowledge can be measured by quantifying the conceptual framework's network size. But does the network's size reflect the real knowledge relevancy? The efficiency of the knowledge application can be illustrated within the roadmapping mechanism. Still, the number of times a given document has been accessed, reflects a value of interest and relevance for the users within the context of the roadmap, but may miss the global value that reflects the completeness, the relevancy and the efficiency of this piece of knowledge given the user's specific requirements.

A good criterion to assess the value of knowledge is an indicator obtained from the user showing whether the knowledge object addressed his specific problem or not. From the innovation point of view, a value criterion could be derived from the number of new innovations created, and may also be linked with the number of knew knowledge objects created. Another criterion may be a measurement of the impact that knowledge (new or already existing) had on speeding up innovation.

All of the mechanisms proposed for the evaluation of innovation and knowledge capability basically rely on measuring maturity. This measurement should serve as an indicator of the ability of the enterprise to evolve. By positioning an enterprise in the maturity domain, it becomes possible to then indicate how such enterprise may evolve within the innovation maturity life cycle. Maturity levels are thus part of the innovation value indicator.

For knowledge management maturity, four levels are proposed:

(i) LEVEL 1 - Product and Process Knowledge: It describes the core competencies of the company and is constituted of cumulated experiences of experts. Best practices may however, not be shared and the global process may not be formalised and optimised. This level is characterised by a high proportion of tacit knowledge. These experts may decide to formalise their way of working and decide to introduce rational operational decision process. This then leads to the second maturity level.

(ii) LEVEL 2 - Improvement Knowledge: This is the explicit enterprise knowledge that resides formally in company documents and procedures. Experts build maps of the products and processes deployed and refine them for a better efficiency to obtain a more standard, but flexible knowledge structure. To drive this improvement properly, the concerned stakeholders may feel the need to formalise knowledge to a higher level, considering their way of working together. The optimised enterprise knowledge can subsequently be enriched with tactical management knowledge.

(iii) LEVEL 3 - Collaboration Knowledge: The best practices linking fields and experts in Level 2 are now formalised. Previously, stakeholders introduced enhancements based on a static knowledge mapping representation. In this level the knowledge mapping is now systematised creating a dynamic representation that tactically drives the operational choices. This dynamic mapping is usually generalised or obtained from a higher level of abstraction corresponding to more domainindependent strategic knowledge.

(iv) LEVEL 4 - Generalisation Knowledge: When the Level 3 methodology is mature enough, it can be formalised and re-used by other teams or other domains in the form of a standard. This bottom-up approach may be compared to a top-down strategic decision to use standards in project management (PMBOK), quality (ISO 9001) or on environmental issues (ISO 14001) for example.

The challenge for an enterprise is to position itself on this maturity scale, which requires a thorough understanding of the terms innovation and related knowledge supply chain.

The possible expansion of this knowledge maturity classification mechanism to also include innovation maturity is currently being researched by the two research teams involved in writing this paper. By having the ability to assess maturity of their organisations, managers can identify weak areas and determine a road ahead as to best address those weaknesses.

\section{Example Application in the Financial Services Domain}


In this section two example applications of the roadmapping and conceptual framework tools are briefly discussed. In both applications only parts of the proposed methodology were used. The complete methodology presented in this paper was in fact constructed based on the experiences from the two example applications. The applications described here therefore serve to illustrate the advantages of using roadmaps and conceptual frameworks for managing innovation, as well as highlighting the problems experienced by not using these tools.

\subsection{Roadmapping example}

This example explains the use of roadmaps to plan and implement an innovation project within a large insurance company. This particular project had three year duration and commenced in the last quarter of 2003. The high costs and long policy issuance times for new business administration have forced the company to look for innovative ways to improve their new business process (the process for capturing new polices on their systems and issue the policies). A complete Innovation Life Cycle process has been executed during this innovation project.

\subsubsection{Identification, assessment, and planning of the innovation project}

A Master Plan roadmap was constructed and used to guide the whole planning process of the innovation project. This Master Plan Roadmap is illustrated in Figure 10. An innovation management software platform called EDENTM (developed by Indutech (Pty) Ltd [8]) was used to build the roadmap and manage the knowledge and information required for and created during the execution of the innovation project.

Figure 10. Master Plan for Insurance Innovation Project

The first phase in the innovation project was to identify possible innovative solutions for improving the insurance company's new business process. In order to do this it was first required to get a good understanding of the current enterprise processes, costs, and strategies. Due to the lack of explicit knowledge on the processes and costs, a lot of time was spent in extracting the required knowledge from experts via interviews. Some of the knowledge was captured in process diagrams and documents, but these were incomplete and scattered around in different departments. Knowledge collected during this first phase was captured in documents and stored within the information repository of the Master Plan roadmap using the EDENTM software environment. At the same time information on new technologies for the insurance industry was collected by scanning the external environment. This information was also captured in the Master Plan roadmap. After a thorough understanding of the current enterprise and the problem areas was obtained (the As-Is scenario), possible innovative solutions were identified for implementation. Specifically, tele-underwriting was identified as a new technology that could significantly reduce the costs and issuance times for the new business process.

The next step was to assess the impact of this new technology on the business and conceptually design and define the To-Be enterprise architecture, should this technology be implemented. Projects for implementing the new technology also had to be defined. At the end of this process a complete Master Plan Roadmap was obtained that identified the specific projects that need to be executed in order to implement the new tele-underwriting process. This Master Plan roadmap contained most of the information and knowledge the design teams required to do the detail design of the new tele-underwriting policy capturing process. This significantly speeded up the design process.

Due to the lack of an overall model of the enterprise and the fact that current knowledge about the enterprise operation was not explicitly captured and managed, a lot of time was spent initially trying to understand the current enterprise. Should a conceptual framework model of the current enterprise had been available at the start of the project, the time required for planning the innovation project could have been greatly reduced.

\subsubsection{Design and implementation}

This phase involved the detailed design of the tele-underwriting process (processes, information systems, etc.), as well as the implementation (roll-out and training of personnel). Again roadmaps were constructed to guide the project teams by providing them the relevant information and knowledge they require to execute their tasks (in context of where it is required). All knowledge developed during the design and implementation process was also captured for future use. Figure 11 illustrates the roadmap structures used to guide the different design and implementation teams. EDEN ${ }^{\mathrm{TM}}$, a collaborative innovation management software platform, enabled integration and knowledge sharing between the different roadmaps. 
Benefits and gaps will be analysed in section 4.3.

Figure 11. Roadmap Structure for Design and Implementation Teams

\subsection{Conceptual framework example}

The second example illustrates how Conceptual Frameworks were used to plan an innovation project within another insurance company. This project was executed over a 9 month period starting in April 2004. The high degree of complexity contained in a contractual document (i.e. the Master Contract) - a sizable agreement between the client (i.e. the policyholder) and the insurance company (i.e. the insurer) resulted in the situation where employees, clients and intermediaries found it extremely difficult to interpret, understand and apply the contents of this contract. The complexity of this contract further made it extremely difficult to update the contract with changes necessitated by changes to the product offering of the relevant insurance company. The contract further contained possible legal loopholes due to inconsistent updating in the past as well as ambiguous terminology and clauses, creating a possible legal risk to the insurer. The brief for this project was firstly to analyse and suggest ways to simplify this Master Contract (MC) (i.e. Phase 1 of the project) and subsequently looking at ways to reduce the complexity of the business as a whole (i.e. Phase 2 of the project). Reviewing the insurance company's benefit structure was suggested as a starting point for reducing the complexity of the business.

Everything, except the implementation part of the Innovation Life Cycle process has been executed during this particular innovation project as the client implemented the innovation using internal resources.

\subsubsection{Identification, assessment, and planning of the innovation project}

a. Phase 1:

The initial project activities revolved around analysing the Master Contract and extracting key entities from its contents (e.g. types of policyholders, types of disability states, names of related documents, types of claims, types of benefits, etc.) and capturing these in a Conceptual Framework. All occurrences of these entities, in the content of the contract, were further linked to the entities in question. Subsequently, relations between the different entities were established by interpreting the content of the contract as well as by interviewing experts. The Conceptual Framework was then updated with these relations, resulting in a network of entities with their respective interdependencies, which was then used as a mechanism to get a shared understanding about the current contract as well as a means of analysing its content and structure.

b. Phase 2:

After the suitable changes to the contract and relating entities were proposed, the next step was to investigate the possibilities around simplifying the business as a whole. This implied broadening the scope of the Conceptual Framework to include the entire organisation with the goal to understand the current situation to be able to identify suitable areas for simplification. Several documents were studied and experts interviewed to understand the value chain of the insurer. The Conceptual Framework was expanded throughout this process with information about, and relations between, significant stakeholders, processes, business rules, products, key documents, IT systems, benefits, etc. The expanded Conceptual Framework served as a model of the current organisation and was used to analyse the organisation for possible simplification areas after a common understanding was reached among the team members.

In summary, the Conceptual Framework was used to understand the domain in which the relevant innovation project was to be executed in.

\subsubsection{Design and implementation}

a. Phase 1:

Once the significant parts of the Master Contract and its immediate surroundings were modelled in the Conceptual Framework, it was used to:

(i) Identify duplicate terms for the same entity (e.g. accident policyholder and accident member) as candidates for simplification to reduce the complexity of the contract and increase the ease of understanding.

(ii) Estimate the impact of removing problematic contract clauses (identified by experts as well as modellers) from the contract in order to decrease ambiguity and complexity. More specifically, the Conceptual Framework enabled one to focus on a given contractual clause and to see all other entities that relates to it (e.g. other clauses, benefits, claim requirements, etc.). This made the task of determining what other parts of the contract to consider, due to a change in a given clause of the contract, fairly easy. 
(iii) Identify entities falling outside the scope of the contract, which might be impacted by any changes to the contract, that need to be investigated further (e.g. other documents, products, stakeholders, processes, business rules), etc.

(iv) Identify a more suitable structure for the contract by grouping all closely related clauses together in order to minimise the number of cross-references as a means of increasing the ease interpreting the contents of the contract. This proposed change would not have been apparent without the aid of a Conceptual Framework.

b. Phase 2:

Once the Conceptual Framework has been extended to include all significant parts of the entire organisation, it was used to:

(i) Analyse the complexities of the organisation and identifying the most feasible improvement opportunity.

(ii) Estimating and agreeing on the impact of the changes proposed on the organisation as a whole. In summary, the Conceptual Framework was used to highlight and specify the relevant changes required to reach the project goals.

\section{Synthesis}

In the first example, several benefits were observed as result of using roadmaps as knowledge management tools to guide the innovation process:

(i) Information and knowledge can easily be shared and used for collaboration, since it is captured within context in the roadmap structure. This improves both the time and effectiveness of the development and implementation of innovation.

(ii) Knowledge transfer between different teams in the life cycle phases of the innovation project is quicker and more effective.

(iii) Individual knowledge becomes group memory.

(iv) New team members can quickly be brought up to speed. All information on the project, additional information as well as information generated during the project, is stored in context by storing the information in the relevant step within the roadmap. The new member can therefore immediately see the whole outline of the project as well as all knowledge in context currently possessed in the project.

(v) Development and implementation knowledge is captured for re-use in future improvement or innovation projects. This speeds up the initiation of future projects.

However, a difficulty experienced was the effort required to analyse and synthesize a vast amount of multidisciplinary knowledge captured in the roadmaps. Since Conceptual Framework modelling tools were not available at the start of the project, it was difficult to fully understand the complexity and interrelationships of all aspects of the organisation and processes studied. If this had been available, it could have been used in the planning and initiation phases to increase the level of understanding and to speed up the identification and planning of specific innovation projects.

The most significant benefits using a Conceptual Framework that became apparent during the execution of the second project example are:

(i) A Conceptual Framework serves as a mechanism to understand and share the intricate relations between the disparate entities of an entire organization (e.g. understand relationships between different processes, IT systems, business rules and paragraphs of the complex contract document). Reaching a common understanding among the team members about the domain in which the innovation project question is to be executed is thus simplified using a Conceptual Framework.

(ii) It facilitates the process of analysing the domain in order to identify possible innovation opportunities.

(iii) Assessing the impact of proposed changes on the rest of the domain is simplified when using a Conceptual Framework.

(iv) The Conceptual Framework can incorporate views from different stakeholders leading to better buy-in into the innovation project.

However, during the execution of the second project example, the following noteworthy shortcomings and problems were identified:

(i) The Conceptual Framework was not linked to a formal change process (i.e. the roadmapping process), making it difficult to track changes and the progress made.

(ii) The magnitude of user intervention required to create the relevant Conceptual Framework was significant. 
(iii) It was difficult to validate the correctness of the resulting Conceptual Framework.

(iv) It may have been useful to have a time dimension to indicate the growth in the Conceptual Framework throughout the execution of the project.

(v) It was difficult to identify the right level of detail for the Conceptual Framework.

These examples showed us that Conceptual Frameworks enable users to have a better understanding of the domain or environment, thereby making it easier to identify new opportunities for innovation. The Conceptual Framework also helps to identify and specify the roadmaps required to guide the innovation projects. Roadmaps guide the development and diffusion of the new knowledge and ensure that the knowledge is captured within context. It then helps to speed up future innovation projects having a structured and contextual access to the knowledge gained in the current innovation project.

\section{Conclusion}

The level of maturity of Knowledge Management tools has increased significantly in the past decade. While the tools previously required external expertise to help build and maintain a specific knowledge domain, it can now be built and maintained more dynamically. This is made possible by the development of new collaboration tools.

Roadmaps contribute by creating a common reference for project objectives. But users are still responsible for ensuring that the combination of knowledge objects captured is an acceptable quality. It is often not simple to assess and evaluate the vast amount of knowledge captured. Another tool is thus required to deal with this complexity. Conceptual frameworks constitute a navigable virtual network that helps to identify the possible relevant connections in the real environment, thereby making the vast amount of knowledge more accessible to the knowledge analyst within the context of his selected research domain, and in some cases helping to identify solutions for an innovation problem.

The combination of these two tools expands the feasibility and usability of a global and integrated knowledge network that would increase the innovative synergies in and between organisations. The different steps encountered by this evolution highlight an increasing level of management maturity. The modelling of domain expertise and project expertise, combined with the latest advances in informatics (processing power, storage and connectivity) opens opportunities to achieve a more advanced maturity level: an integrated network of organisations willing to collaborate by positioning their systems, processes and people in such a way as to allow for the transfer of information and knowledge between the organisations. With this, information and knowledge are automatically maintained by the natural activities of its users, while the information system enables useful access to relevant knowledge, thus enabling efficient collaboration and innovation.

Future research should explore how knowledge within integrated knowledge networks can be managed across the entities within the network in order to increase innovation levels. The use of roadmaps and conceptual frameworks should form the basis of this research. The application of Conceptual Frameworks is still immature, and research should be conducted on how best to construct, implement, and maintain such a framework.

In order to successfully measure the value and ability of organisations within an integrated knowledge network to perform innovation projects, research should be conducted in measuring the maturity of organisations to execute innovation projects, and to determine the value of such innovation early on.

\section{Acknowledgements}

This research is part of a collaboration project between two research teams supported by the National Research Foundation (NRF) in South Africa and the National Council for Scientific Research (CNRS) in France.

\section{References}

Bellinger, G (2004). Knowledge Management-Emerging Perspectives. http://www.systemsthinking.org/kmgmt/kmgmt.htm\#bel97b.

Booch, G, Rumbaugh, J and Jacobson, I (1998). The Unified Modelling Language - User Guide. AddisonWesley.

Burgelman, RA, Miadique, MA and Wheelwright, SC (2001). Strategic Management of Technology and Innovation. New York: McGraw-Hill/Irwin. 
Candlot, A, Ammar-Khodja, S, Mauchand, M and Perry, N (April 2005). Réflexion sur une approche systématique pour créer des structures de consolidation de l'information. 9ème Colloque National AIP PRIMECA. La Plagne.

Carneiro, A (2000). How does knowledge management influence innovation and competitiveness? Journal of knowledge Management, vol. 4, no. 2, pp. 87-98

Cassin, B (2004). In: Vocabulaire Européen des Philosophies. Seuil, Le Robert, ISBN 2-85-036-580-7, ISBN 2-02-030730.

Co-operative Technology Roadmapping (2003). TOA, TU Delft.

Darroch, J and MacNaughton, R (2002). Examining the link between knowledge management practices and types of innovation. Journal of Intellectual Capital, vol. 3, no. 3, pp. 210-222.

Davenport, TH and Prusak, L (1998). Working Knowledge: How Organizations Manage What They Know. Boston, MA: Harvard Business School Press.

Defining a Roadmap (2004). Indutech internal white paper.

Donofrio, N (2004). Innovation: The New Reality for National Prosperity. 21st Century Innovation Working Group Recommendations, Version 2.1, December 15, 2004.

Drucker, P (1985). Innovation and Entrepreneurship: practise and principles. London: Heinemann.

Du Plessis, M. (2005). Drivers of knowledge management in the corporate environment, International Journal of Information Management, Volume 25, Issue 3, ISSN: 0268-4012, June 2005, pp.193-202.

$E D E N^{\mathrm{TM}}$ Software. Indutech (Pty) Ltd. http://www.indutech.co.za/products.htm

Frank, C. and Gardoni, M., (2005). Information content management with shared ontologies at corporate research centre of EADS, International Journal of Information Management, Volume 25, Issue 1, ISSN: 0268-4012, February 2005, Pages 55-70.

Grundstein, M and Rosenthal-Sabroux C (October 1999). Système d'information et Capitalisation des connaissances : un enjeu nouveau pour la conception de système d'information. Prédit.

Gunnlaugsdottir, J., (2003). Seek and you will find, share and you will benefit: organising knowledge using groupware systems, International Journal of Information Management, Volume 23, Issue 5, ISSN: 0268-4012, October 2003, Pages 363-380.

IBM's Global Innovation Outlook (2005).

Johannessen, JA, Olsen, B and Olaisen, J (1999). Aspects of innovation theory based on knowledgemanagement. International Journal of Information Management 19, pp. 121-139.

Kappel, TA (2001). Perspectives on roadmaps: how organizations talk about the future. The Journal of Product Innovation Management 18, pp. 39-50.

Kemp, RGM, Folkeringa, M, de Jong, JPJ and Wubben, EFM. Innovation and firm performance. Research Report H200207, ISBN: 90-371-0875-X.

Kostoff, RN and Schaller, RR (2001). Science and technology roadmaps. IEEE Transactions on Engineering Management, vol. 48, issue 2, pp. 132-143.

Leiponen, A (2006). Managing Knowledge for Innovation: The Case of Business-to-Business Services. Journal of Product Innovation Management, 23, pp. 238-258.

Lemon, M and Sahota, PS (2004). Organizational culture as a knowledge repository for increased innovative capacity. Technovation, no. 24, pp. 483-498.

Lööf, H and Heshmati, A. ON THE RELATIONSHIP BETWEEN INNOVATION AND PERFORMANCE: A SENSITIVITY ANALYSIS, Royal Institute of Technology, Industrial Economics and Management. The United Nations University, UNU/WIDER. First Version May 2001, Revised October 2001, March 2002, December 2002.

Managing Engineering Knowledge, MOKA (2001). Methodology for Knowledge Based Engineering Application, Edited by Melody Stokes for the MOKA Consortium.

Minsky, M (Fall 1982). Why People Think Computers Can't. AI Magazine, vol. 3, no. 4.

Next-Generation Manufacturing, A Framework for Action, Executive Overview, January 1997, Copyright (C)1997 Agility Forum, Leaders for Manufacturing, and Technologies Enabling Agile Manufacturing.

Nonaka, I (1991). The knowledge-creating company. Harvard Business Review, vol. 69, no. 6, pp. 96104.

Park, Y and Kim, S (2005). Linkage between knowledge management and R\&D management. Journal Of Knowledge Management, vol. 9, no. 4, pp 34-44.

Pera Master Planning Handbook (1996). Purdue University. http://www.pera.net/Arc_pera.html

Pérez-Bustamante, G (1999). Knowledge management in agile innovative organizations. Journal of Knowledge Management, vol. 3, no. 1, pp. 6-17. 
Phaal, R, Farrukh, CPR and Probert, DR (2001). A framework for supporting the management of technological innovation. THE FUTURE OF INNOVATION STUDIES CONFERENCE, 20 - 23 September 2001, University of Technology: Eindhoven.

Phaal, R, Farrukh, CJP and Probert, DR (January 2004). Technology roadmapping-A planning framework for evolution and revolution. Technological Forecasting and Social Change, vol. 71, no. 1, pp. 5-26.

Prax, JY (2000). Le guide du Knowledge Management- concepts et pratiques du management de la connaissance. Dunod.

Racunas, S and Shah, N. A Conceptual Framework for Hypothesis Testing and Evaluation. The Pennsylvania State University.

Rus, I, Lindvall, M and Sinha, SS. Knowledge Management in Software Engineering:A State-of-the-ArtReport. http://www.thedacs.com/techs/kmse/kmse.html.

Salvendy, G (1992). Handbook of industrial engineering. Canada: John Wiley \& Sons.

Swan, J, Newell, S, Scarbrough, H and Hislop, D (1999). Knowledge management and innovation: networks and networking. Journal of Knowledge Management, vol. 3, no.4, pp. 262-275.

The Boston Consulting Group (BCG), Inc. (2005). BCG Senior Management Survey 2005. USA. Available from www.bcg.com.

Tidd, J, Bessant J, and Pavitt, K (2001). Managing Innovation: Integrating technological, market and organizational change. England: John Wiley \& Sons Ltd.

Tiwana, A (2001). The Knowledge Management Toolkit: Practical Techniques for Building Knowledge Management Systems. Englewood Cliffs, NJ: Prentice-Hall.

Van't Hof, C (2003). Good Practices in Managing Knowledge. 3rd European Knowledge Management Summer School 7-12 Sept, 2003, Spain: San Sebastian.

Wielinga, B (1992). KADS modeling approach to knowledge engineering . London, UK: academic press. 


\section{Bibliography}

N.PERRY

Nicolas Perry received his $\mathrm{PhD}$ in Mechanical Engineering from the University of Nantes and Ecole Centrale de Nantes (Fr) in 2000. He is an Associate Professor at Ecole Centrale de Nantes and works in the Research Institute of Communication and Cybernetics of Nantes. His research topics focus on Virtual Engineering, Knowledge Management and KBE as Decision Tools for Engineers applied to Cost Management.

\section{W.UYS}

Wilhelm UYS is a $\mathrm{PhD}$ student at the Global Competitiveness Center at Stellenbosh University in the Department of Industrial Engineering (RSA). He is working on the relation between document and knowledge, using ontologies approach in order to support the roadmapping method develop for managing innovative projects.

\section{Figures}

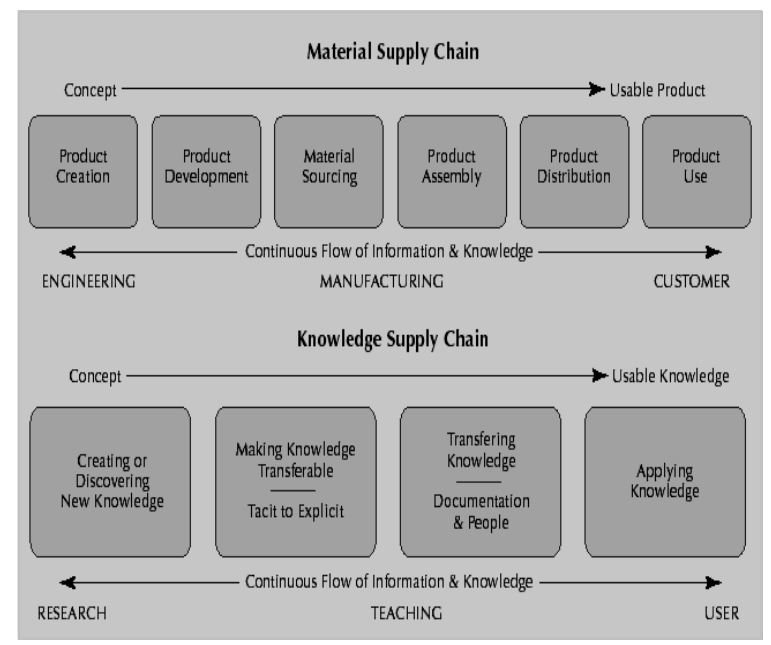

Figure 1: The Knowledge Supply Chain

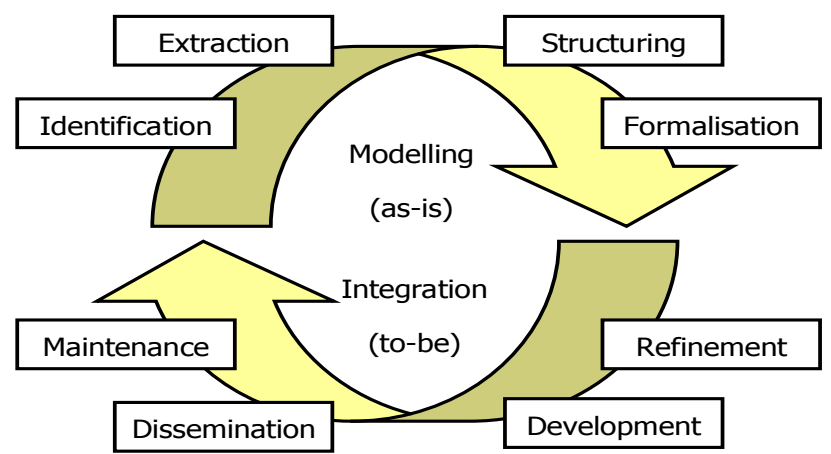

Figure 2: The Knowledge Life Cycle (Candlot et al., 2005) 


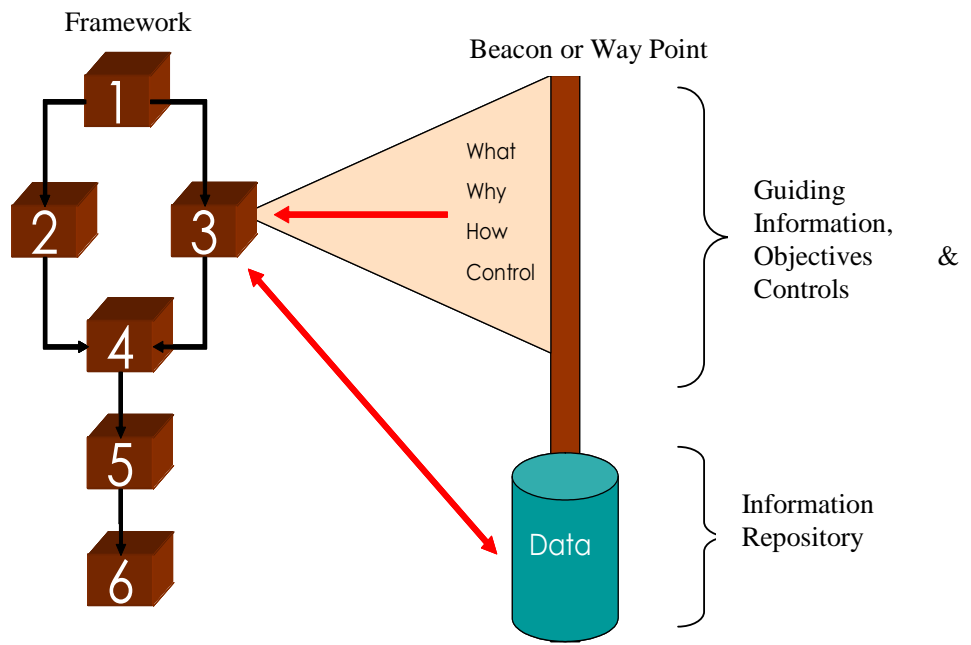

Figure 3: Roadmap with Guiding Structure and Beacons

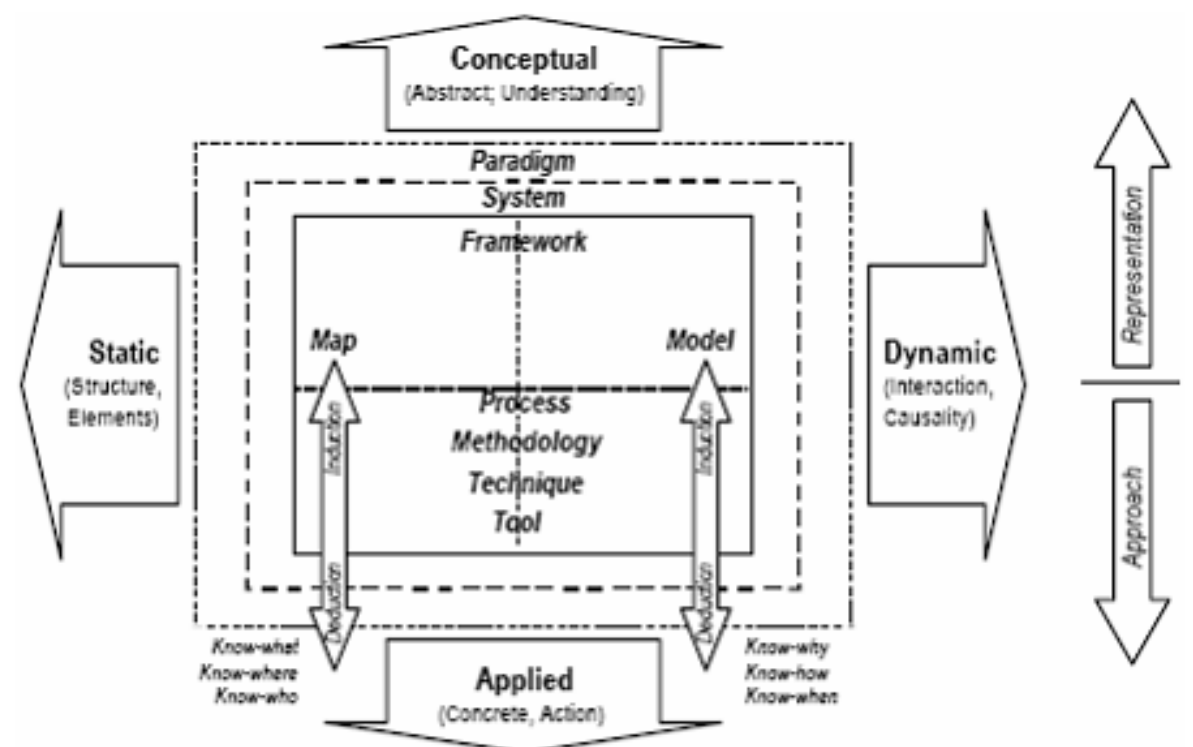

Figure 4: A Meta-framework for Management Representations and Approach 


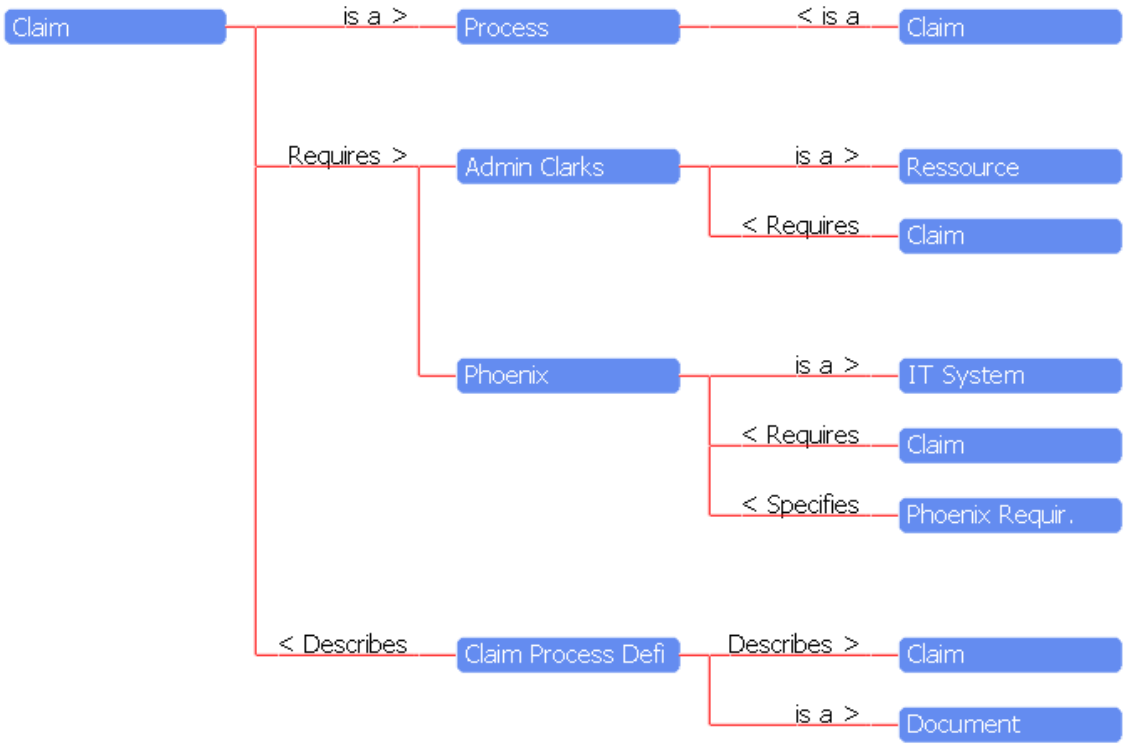

Figure 5: Example of Entities and Relations in the Conceptual Framework of a Life Insurance Company

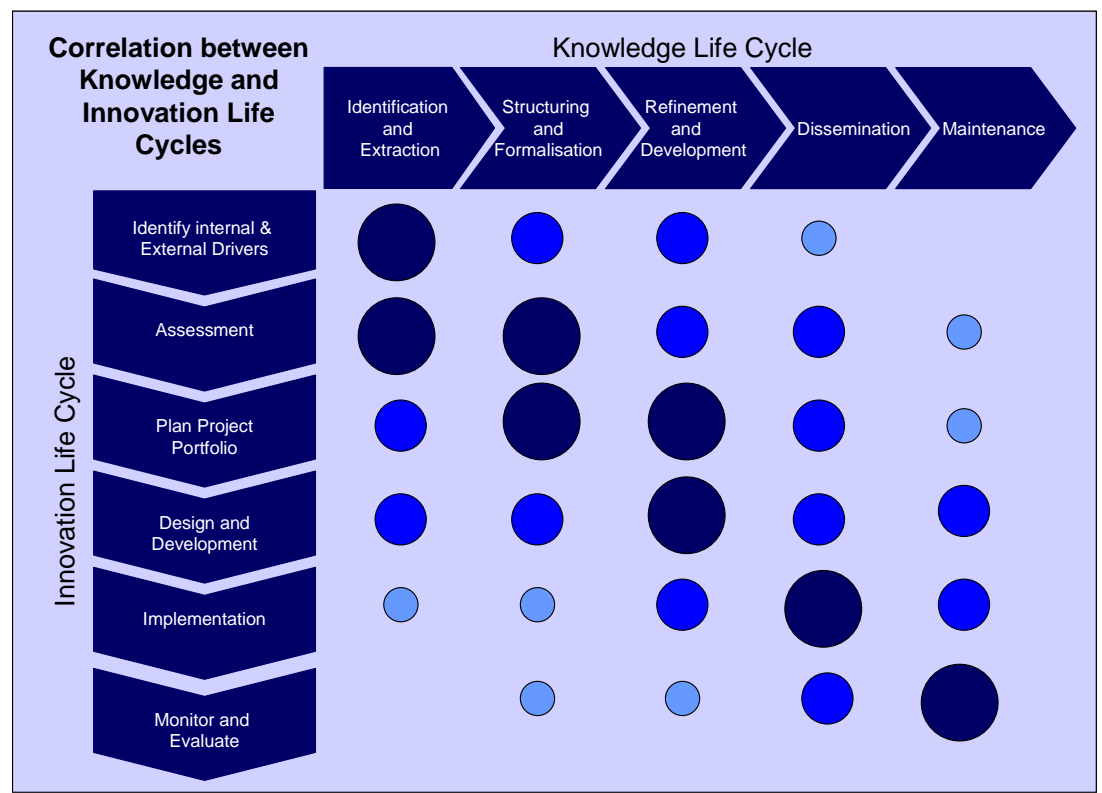

Figure 6: The Correlation between Knowledge and Innovation Life Cycles 


\section{Innovation Life Cycle Model}

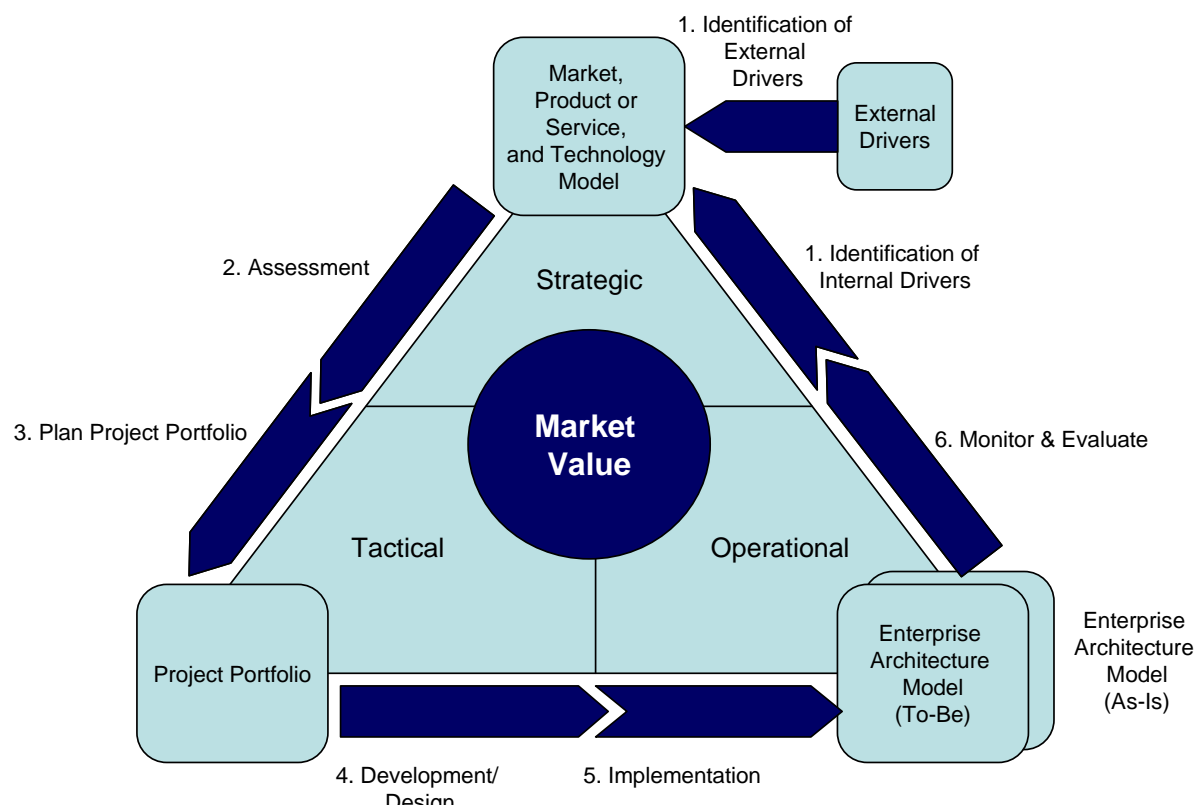

Design

Figure 7: Innovation Life Cycle Model

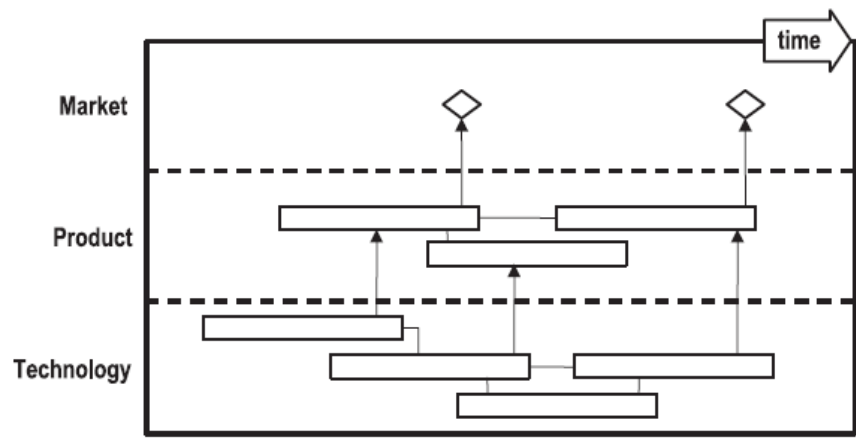

Figure 8: Schematic Technology Roadmap, showing how Technology can be aligned to Product and 


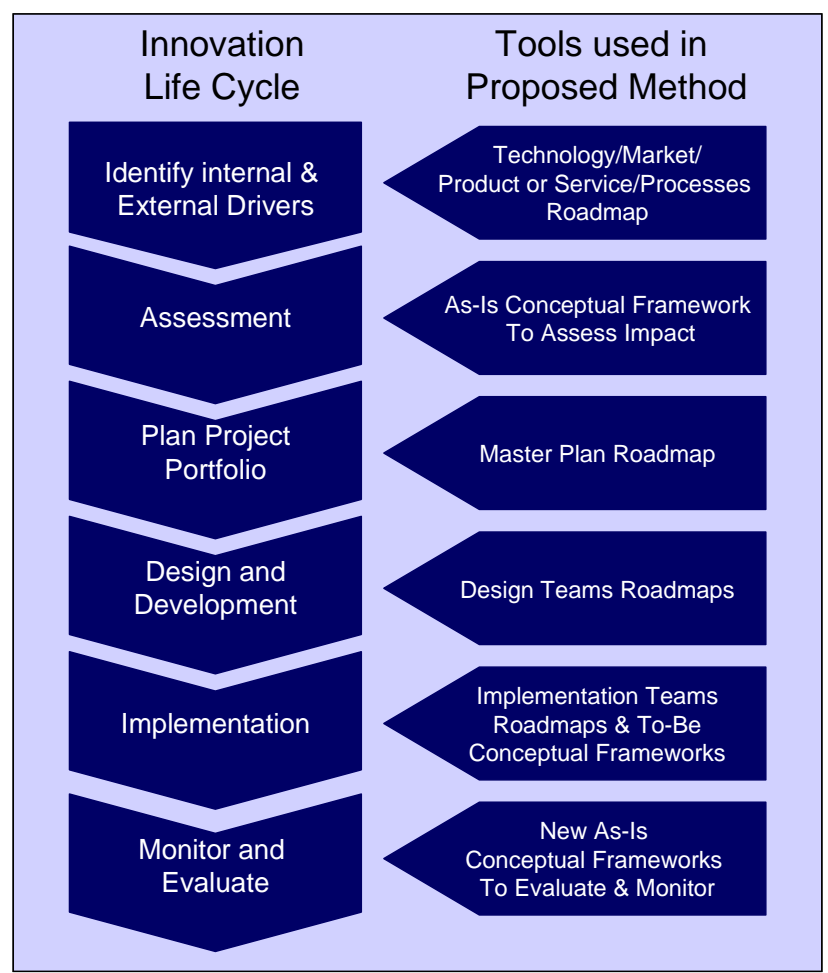

Figure 9: Tools to be used in the Proposed Methodology

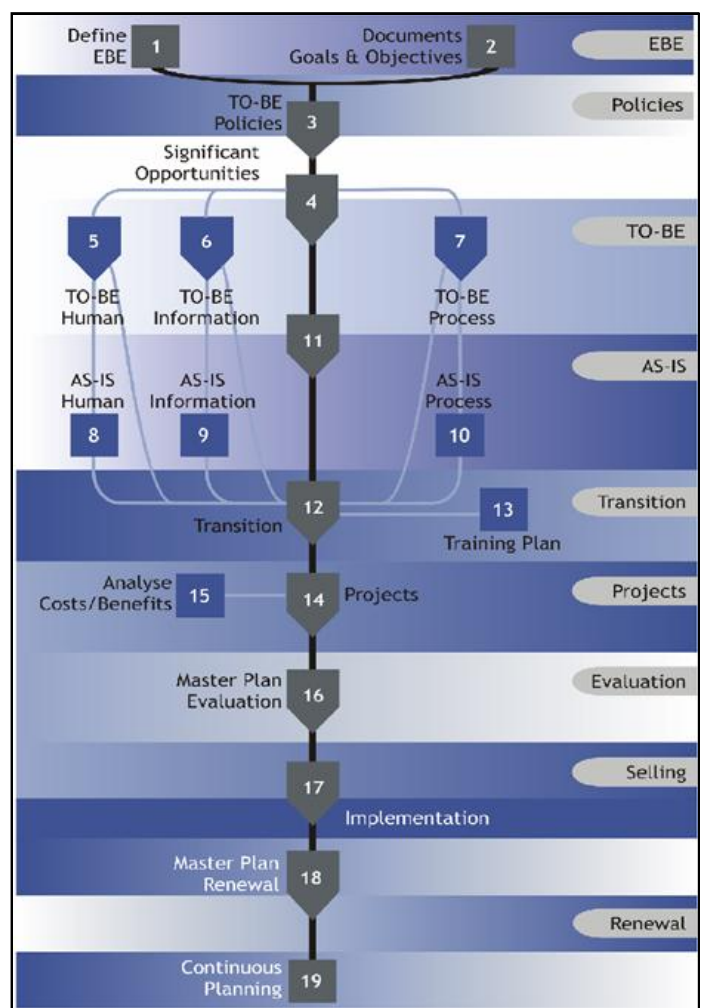

Figure 10. Master Plan for Insurance Innovation Project 


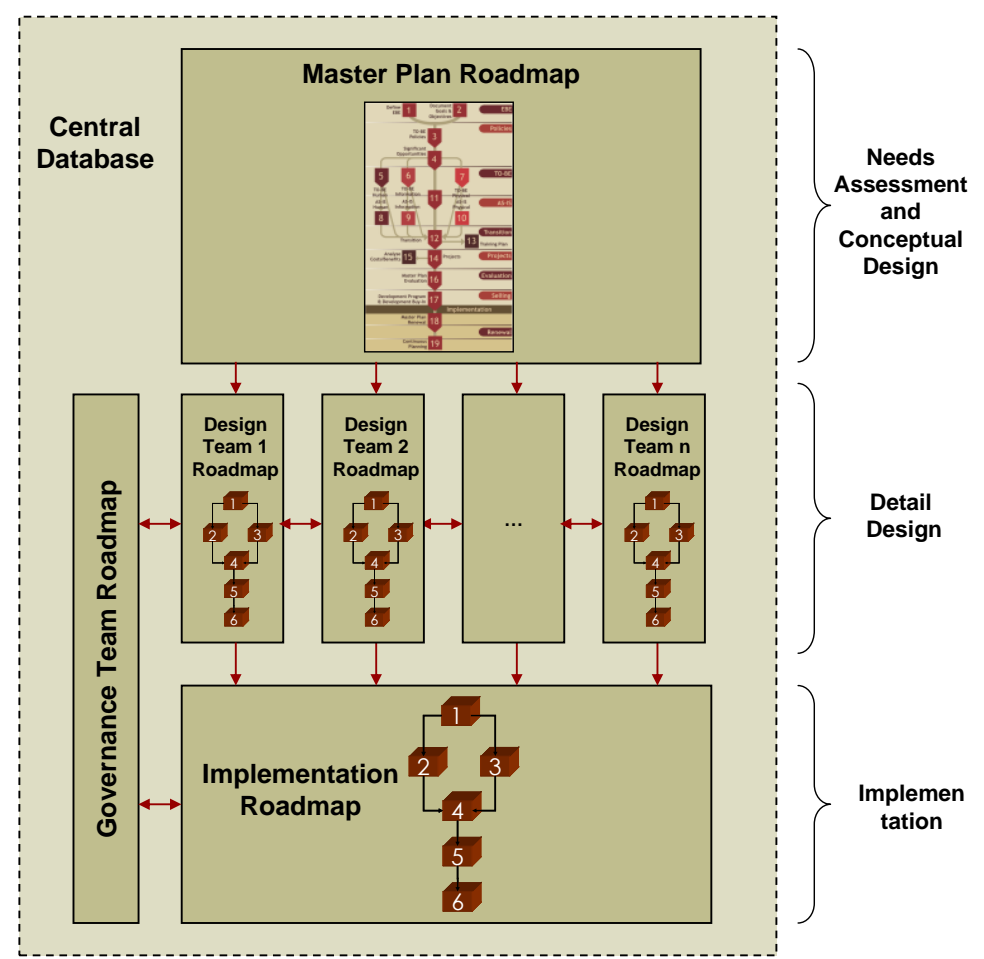

Figure 11. Roadmap Structure for Design and Implementation Teams 